\title{
Kajian pola arus di daerah penangkapan bagan apung di Desa Tateli Weru
}

\author{
Study of current patterns in the fishing ground of boat lift net in Tateli Weru Village
}

DONNY TULUNGEN*, PATRICE N.I. KALANGI dan WiLHELMinA PATTY

Program Studi Pemanfaatan Sumberdaya Perikanan, Fakultas Perikanan dan Ilmu Kelautan, Universitas Sam Ratulangi, Manado 95115

\begin{abstract}
One of the factors that should be known in the utilization of fish resources is the oceanographic parameters, and currents are a parameter that receives a lot of attention. Surface currents data from waters off Tateli Weru Village particularly in the fishing operation of boat lift nets is, however, not available yet, therefore it is necessary to do a research to understand the pattern of surface currents relating to the tides. This study aimed to describe the direction and speed of tidal currents and mapped tidal flow the area. Current measurements were done based on the Eularian method and the tidal heights were observed using a palm tide.
\end{abstract}

Keywords: tides, current, direction, speed, boat lift net, Tateli Weru Village

\begin{abstract}
ABSTRAK
Salah satu faktor yang harus diketahui dalam pemanfaatan sumber daya ikan, adalah parameter oseanografi, dan arus merupakan parameter yang banyak mendapat perhatian. Akan tetapi data mengenai arus permukaan perairan Desa Tateli Weru khususnya di daerah pengoperasian bagan apung belum tersedia, sehingga perlu dilakukan penelitian untuk melihat pergerakan arus permukaan saat pasang dan surut. Penelitian ini bertujuan untuk mendeskripsikan arah dan kecepatan arus pasut, serta memetakan pola arus pasut sekitar daerah penangkapan bagan apung di perairan desa Tateli Weru. Secara spesifik pengukuran arus dilakukan dengan menggunakan cara Eularian, sedangkan untuk mengukur pasut menggunakan cara pengamatan langsung pada palem pasut.
\end{abstract}

Kata-kata kunci: pasang surut, arus, arah, kecepatan, bagan apung, Desa Tateli Weru

\section{PENDAHULUAN}

Kawasan perairan Desa Tateli Weru Kabupaten Minahasa, sampai saat ini telah dimanfaatkan untuk berbagai kegiatan seperti pelayaran, pelabuhan, dan penangkapan sumber daya hayati perikanan terlebih khusus penangkapan sumber daya ikan. Salah satu alat tangkap yang banyak digunakan di daerah ini adalah bagan apung.

Dalam pemanfaatan sumber daya ikan, salah satu faktor yang harus diketahui adalah parameter oseanografi, misalnya arus. Arus laut mempunyai peranan penting dalam sistem ekologi laut (Martono, 2008), keberadaan ikan di fishing ground, dan distribusi ikan (Baskoro dkk., 2004).

*Penulis untuk penyuratan; e-mail: dontu_tomz@yahoo.co.id
Sehubungan dengan hal di atas, ketersediaan data arus dirasakan sangat penting di semua wilayah perairan di Indonesia khususnya di Sulawesi Utara. Sehingga dilakukan penelitian ini di perairan Desa Tateli Weru Kabupaten Minahasa, dengan tujuan untuk mendeskripsikan arah dan kecepatan arus pasut serta memetakan pola arus tersebut.

\section{METODE}

Lokasi penelitian berada di bagian barat daya Teluk Manado pada daerah Tanjung Mandolang dengan posisi geografis $01^{\circ} 26^{\prime} 2.06^{\prime \prime}$ LU -

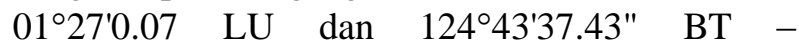
$124^{\circ} 44^{\prime} 29.40^{\prime \prime}$ BT. Arus diukur pada 4 stasiun yaitu: stasiun $1\left(01^{\circ} 26^{\prime} 22.5^{\prime \prime}\right.$ LU dan $124^{\circ} 44^{\prime} 20.3^{\prime \prime}$ 
BT), stasiun $2\left(01^{\circ} 26^{\prime} 05.1^{\prime \prime} \mathrm{LU}\right.$ dan $124^{\circ} 43^{\prime} 47.6^{\prime \prime}$ BT), stasiun $3\left(01^{\circ} 26^{\prime} 41.7^{\prime \prime} \mathrm{LU}\right.$ dan $124^{\circ} 44^{\prime} 03.5^{\prime \prime}$ BT), stasiun 4 (01 ${ }^{\circ} 26^{\prime} 41.22^{\prime \prime}$ LU dan $124^{\circ} 44^{\prime} 23.6^{\prime \prime}$ BT). Pengambilan data dilakukan sebanyak 3 kali survey yakni pertama pada saat bulan purnama, kedua saat perbani akhir, ketiga di antara bulan baru dan perbani awal.

Arah dan kecepatan arus diukur setiap jam selama 24 jam yang dilakukan secara manual dengan metode Eularian pada masing-masing stasiun pengukuran. Sedangkan pengukuran pasut menggunakan cara pengamatan langsung (Djaja, 1989) yaitu pengamatan dilaksanakan dengan membaca skala pada palem pasut yang terkena atau berimpit dengan permukaan air laut setiap jangka waktu tertentu. Pengamatan dan pencatatan tinggi air dilakukan berdasarkan nilai yang tertera pada palem pasut dan dilakukan setiap 1 jam selama 24 jam.

Arah arus diperoleh dengan membaca kompas, sedangkan kecepatan arus dihitung dengan rumus sebagai berikut:

$$
V=s / t
$$

dengan:

$V=$ kecepatan arus $(\mathrm{cm} / \mathrm{s})$

$s \quad=$ jarak yang ditempuh $(500 \mathrm{~cm})$

$t$ = waktu yang ditempuh (det)

Selanjutnya setelah melalui pengolahan dan analisis data dengan program Matlab dan Microsoft Excel, dihasilkan informasi berupa grafik dan gambar sebagai pemetaan arah dan kecepatan arus pasut sehingga bisa didapat pola pergerakan arus pasut di kawasan perairan Desa Tateli Weru.

\section{HASIL DAN PEMBAHASAN}

Berdasarkan frekuensi pasang dan surut di lokasi pengamatan, terindentifikasi bahwa tipe pasang surut saat bulan purnama, perbani akhir dan saat antara bulan baru ke perbani awal adalah termasuk dalam tipe semi diurnal. Hasil ini akan dibahas menurut periode pengamatan.

\section{Bulan Purnama}

Hasil pengamatan arah dan kecepatan arus menurut pergerakan pasut saat bulan purnama disajikan dalam Gbr. 1.
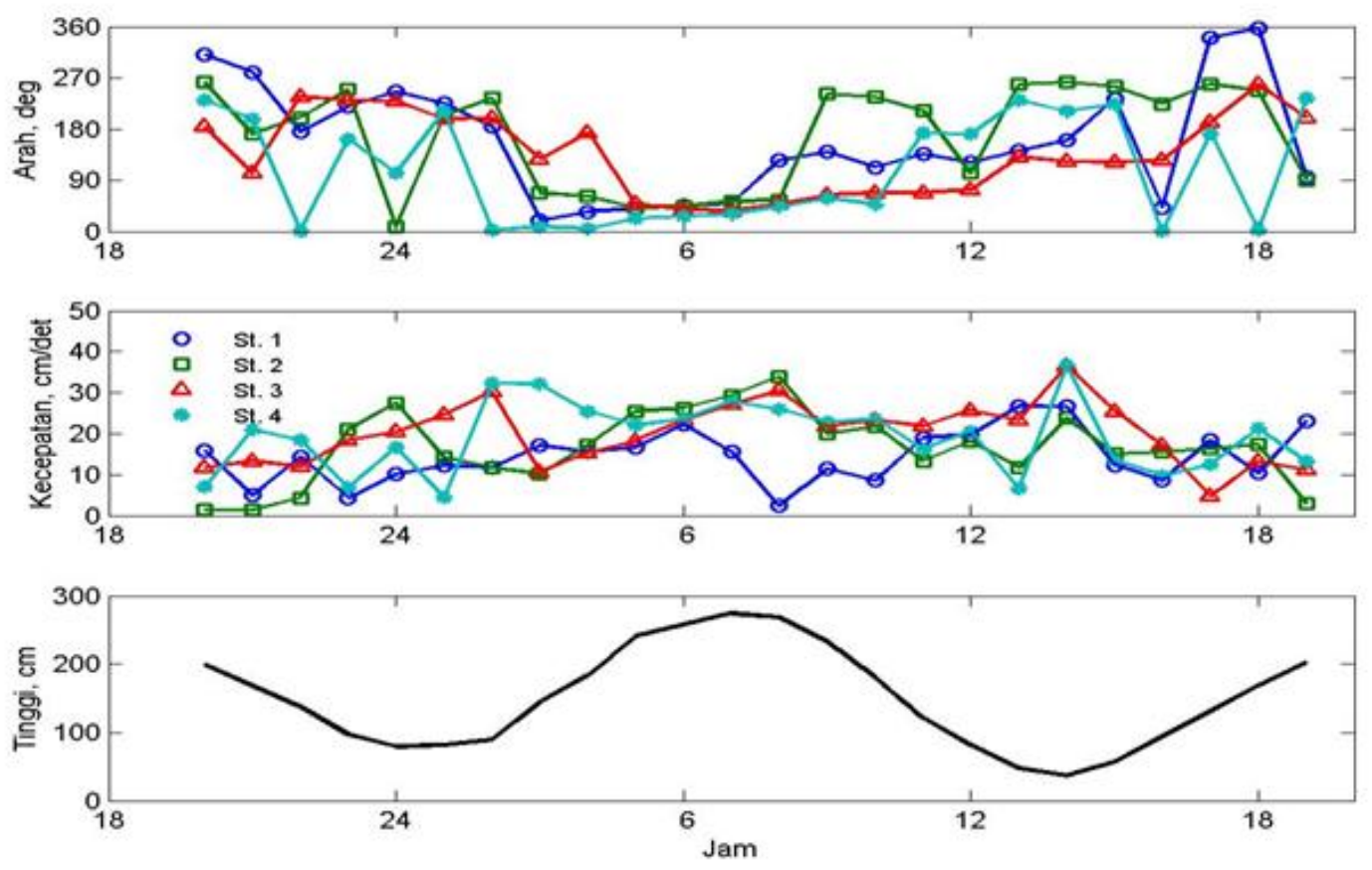

Gambar 1. Arah dan kecepatan arus menurut pergerakan pasang surut saat bulan purnama. 
Pada stasiun 1, arus surut pertama (pukul 20.00-24.00 Wita) bergerak mengarah ke antara barat laut dan selatan dengan kecepatan rata-rata $10 \mathrm{~cm} / \mathrm{det}$; sedangkan arus pasang pertama (pukul 01.00-07.30 Wita), dominan mengarah ke timur laut dengan kecepatan rata-rata $15,90 \mathrm{~cm} /$ det. Selanjutnya arus surut kedua (pukul 08.00-14.00 Wita), dominan mengarah ke tenggara dengan kecepatan rata-rata $16,40 \mathrm{~cm} /$ det, sedangkan arus pasang kedua (pukul 14.30-19.00 Wita) dominan mengarah ke utara dan timur laut dengan kecepatan rata-rata $14,60 \mathrm{~cm} /$ det. Kecepatan ratarata arus saat surut adalah $13,20 \mathrm{~cm} /$ det dan saat pasang adalah 15,20 cm/det (Gbr. 1).

Pada stasiun 2, arus surut pertama (pukul 20.00-24.00 Wita) bergerak dominan mengarah ke selatan dengan kecepatan rata-rata $11,20 \mathrm{~cm} / \mathrm{det}$; sedangkan arus pasang pertama (pukul 01.0007.30 Wita), dominan mengarah ke timur laut dengan kecepatan rata-rata 19,20 cm/det. Selanjutnya arus surut kedua (pukul 08.00-14.00 Wita) dominan mengarah ke barat daya dengan kecepatan rata-rata $20,40 \mathrm{~cm} /$ det, sedangkan arus pasang kedua (pukul 14.30-19.00 Wita) dominan mengarah ke barat daya dan barat dengan kecepatan rata-rata $13,50 \mathrm{~cm} /$ det. Kecepatan rata- rata arus saat surut adalah $15,80 \mathrm{~cm} /$ det dan saat pasang adalah 16,30 cm/det (Gbr. 1).

Pada stasiun 3, arus surut pertama (pukul 20.00-24.00 Wita) bergerak dominan mengarah ke barat daya dengan kecepatan rata-rata 15,20 $\mathrm{cm} /$ det; sedangkan arus pasang pertama (pukul 01.00-07.30 Wita), mengarah ke selatan dan timur laut dengan kecepatan rata-rata $21,40 \mathrm{~cm} /$ det. Selanjutnya arus surut kedua (pukul 08.00-14.00 Wita) dominan mengarah ke timur dengan kecepatan rata-rata 21,40 cm/det, sedangkan arus pasang kedua (pukul 14.30-19.00 Wita) dominan mengarah ke tenggara dan selatan dengan kecepatan rata-rata $14,40 \mathrm{~cm} /$ det. Kecepatan ratarata arus saat surut adalah $20,70 \mathrm{~cm} /$ det dan saat pasang adalah 17,90 cm/det (Gbr. 1).

Pada stasiun 4, arus surut pertama (pukul 20.00-24.00 Wita) mengarah ke barat daya, selatan, utara, dan timur laut dengan kecepatan rata-rata $14 \mathrm{~cm} / \mathrm{det}$; sedangkan arus pasang pertama (pukul 01.00-07.30 Wita), dominan mengarah ke utara dan timur laut dengan kecepatan rata-rata $24 \mathrm{~cm} /$ det. Selanjutnya arus surut kedua (pukul 08.00-14.00 Wita) mengarah ke timur laut dan barat daya dengan kecepatan rata-rata $21,80 \mathrm{~cm} /$ det, sedangkan arus pasang

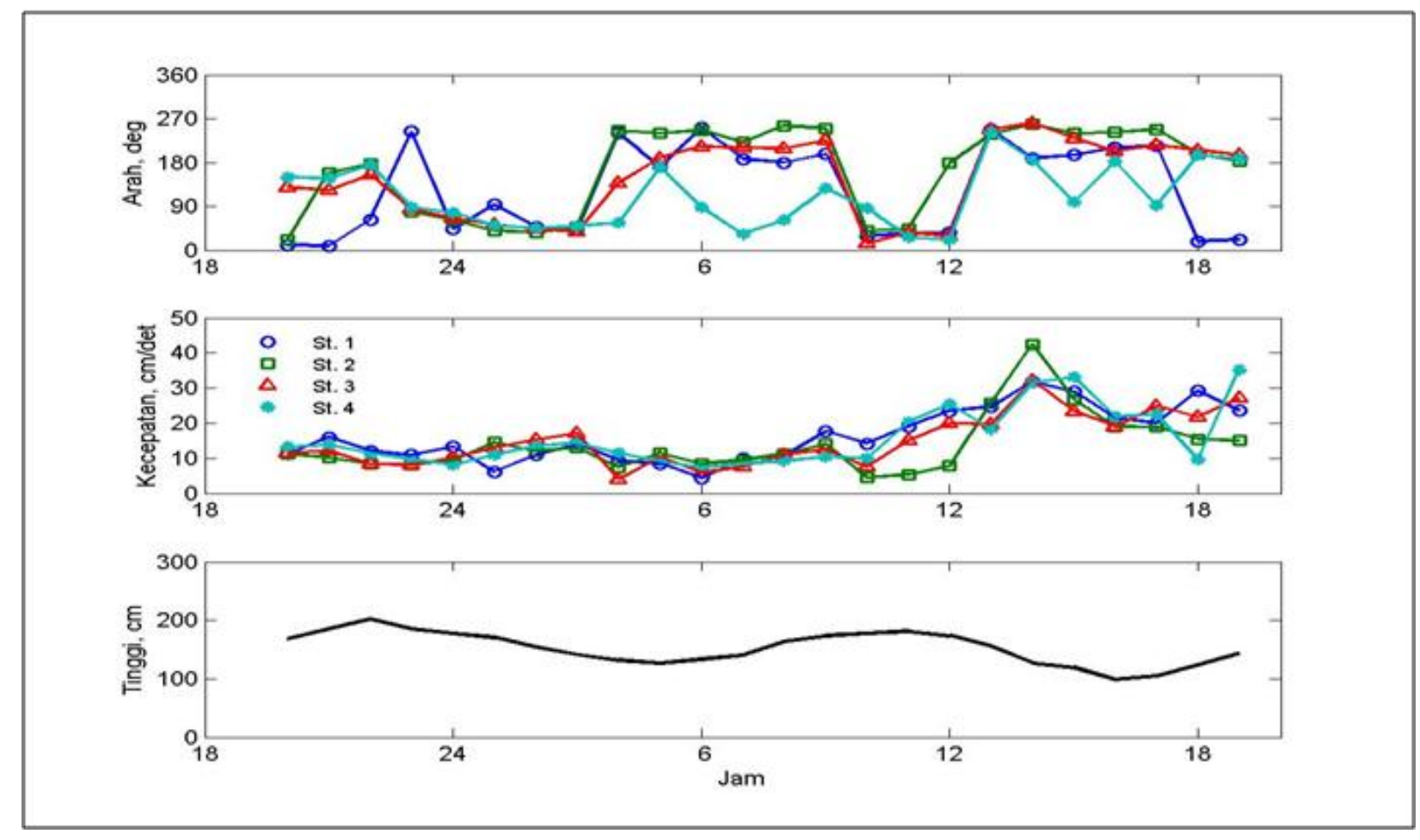

Gambar 2. Arah dan kecepatan arus menurut pergerakan pasang surut saat bulan perbani akhir. 
kedua (pukul 14.30-19.00 Wita) mengarah ke utara dan barat daya dengan kecepatan rata-rata $14,10 \mathrm{~cm} /$ det. Kecepatan rata-rata arus saat surut adalah $17,90 \mathrm{~cm} /$ det dan saat pasang adalah 19,10 $\mathrm{cm} / \operatorname{det}$ (Gbr. 1).

\section{Bulan Perbani Akhir}

Arah dan kecepatannya arus yang diamati selama periode pasang surut saat bulan perbani akhir dapat dilihat pada Gbr. 2. Pada stasiun 1, arus bergerak pasang ketika pengukuran mulai dilaksanakan dengan arah arus dominan ke utara. Kecepatan rata-rata arus pasang pertama adalah $13,10 \mathrm{~cm} /$ det. Arus surut pertama (pukul 23.0005.00 Wita) dominan mengarah ke timur laut dengan kecepatan rata-rata $10,50 \mathrm{~cm} / \mathrm{det}$, sedangkan arus relatif mengarah ke selatan dan timur laut saat pasang kedua (pukul 05.00-11.30 Wita) dengan kecepatan rata-rata $12,70 \mathrm{~cm} /$ det. Saat arus surut kedua (pukul 12.00-16.00 Wita), arus dominan mengarah ke selatan dengan kecepatan arus rata-rata sebesar 26,20 cm/det. Kemudian arus pasang ketiga (pukul 16.30-19.00 Wita), arus dominan mengarah ke utara dengan kecepatan rata-rata $24,40 \mathrm{~cm} /$ det. Kecepatan ratarata arus saat surut adalah $18,30 \mathrm{~cm} /$ det dan saat pasang adalah $16,70 \mathrm{~cm} /$ det (Gbr. 2).

Di stasiun 2, ketika arus pasang pertama (pukul 20.00-22.00 Wita), arus yang dominan mengarah ke selatan dengan kecepatan rata-rata arus adalah $9,90 \mathrm{~cm} /$ det. Arus surut pertama (pukul 23.0005.00 Wita) dominan mengarah ke timur laut dengan kecepatan rata-rata $10,90 \mathrm{~cm} /$ det, sedangkan arus relatif mengarah ke barat daya dan barat saat pasang kedua (pukul 05.00-11.30 Wita) dengan kecepatan rata-rata $8,90 \mathrm{~cm} /$ det. Saat arus surut kedua (pukul 12.00-16.00 Wita), arus dominan mengarah ke barat daya dengan kecepatan rata-rata $24,40 \mathrm{~cm} /$ det. Kemudian arus pasang ketiga (pukul 16.30-19.00 Wita), arus dominan mengarah ke selatan dengan kecepatan rata-rata $16,50 \mathrm{~cm} /$ det. Kecepatan rata-rata arus saat surut adalah $17,60 \mathrm{~cm} /$ det dan saat pasang adalah 11,80 cm/det (Gbr. 2).

Pengamatan di stasiun 3 terlihat bahwa arah arus pasang pertama (pukul 20.00-22.00 Wita) lebih dominan ke tenggara dengan kecepatan ratarata arus sebesar $10,70 \mathrm{~cm} /$ det. Sedangkan arus surut pertama (pukul 23.00-05.00 Wita) dominan mengarah ke timur laut dengan kecepatan rata-rata $11,20 \mathrm{~cm} /$ det. Arah arus dominan ke barat daya saat arus pasang kedua (pukul 05.00-11.30 Wita), dengan kecepatan rata-rata $9,90 \mathrm{~cm} /$ det.
Sedangkan arus surut kedua (pukul 12.00-16.00 Wita) mengarah ke barat dan barat daya, dengan kecepatan rata-rata sebesar 22,90 $\mathrm{cm} /$ det. Kemudian arus pasang ketiga (pukul 16.30-19.00 Wita) dominan mengarah ke barat daya dengan kecepatan rata-rata $24,60 \mathrm{~cm} /$ det. Kecepatan ratarata arus saat surut adalah $17,10 \mathrm{~cm} /$ det dan saat pasang adalah 15,10 cm/det (Gbr. 2).

Pengamatan di stasiun 4 terlihat bahwa arah arus pasang pertama (pukul 20.00-22.00 Wita) mengarah ke tenggara dengan kecepatan rata-rata arus sebesar 12,80 $\mathrm{cm} /$ det. Sedangkan arus surut pertama (pukul 23.00-05.00 Wita) dominan mengarah ke timur laut dengan kecepatan rata-rata $11 \mathrm{~cm} /$ det. Arah arus ke timur laut, timur, dan tenggara saat arus pasang kedua (pukul 05.00$11.30 \mathrm{Wita})$, dengan kecepatan rata-rata $11 \mathrm{~cm} /$ det. Sedangkan arus surut kedua (pukul 12.00-16.00 Wita) mengarah ke utara, barat daya, dan timur dengan kecepatan rata-rata sebesar $26,10 \mathrm{~cm} /$ det. Kemudian arus pasang ketiga (pukul 16.30-19.00 Wita) dominan mengarah ke selatan dengan kecepatan rata-rata $22,50 \mathrm{~cm} /$ det. Kecepatan ratarata arus saat surut adalah $18,50 \mathrm{~cm} /$ det dan saat pasang adalah $15,40 \mathrm{~cm} / \mathrm{det}$ (Gbr. 2)

\section{Bulan Baru ke Perbani Awal}

Hasil pengamatan arah dan kecepatan arus selama bulan baru ke perbani awal disajikan pada Gbr. 3 . Pada stasiun 1, arus bergerak pasang ketika pengukuran mulai dilaksanakan dengan arah arus ke tenggara dan barat daya. Kecepatan rata-rata arus pasang pertama adalah $6,40 \mathrm{~cm} /$ det. Arus surut pertama (pukul 22.00-02.00 Wita) dominan mengarah ke selatan dengan kecepatan rata-rata 10 $\mathrm{cm} / \mathrm{det}$, sedangkan arus relatif mengarah ke barat dan barat daya saat pasang kedua (pukul 03.00$09.00 \mathrm{Wita})$ dengan kecepatan rata-rata $10 \mathrm{~cm} /$ det. Saat arus surut kedua (pukul 09.30-16.00 Wita), arus mengarah ke barat, utara, selatan, dan tenggara dengan kecepatan rata-rata sebesar 16,60 $\mathrm{cm} /$ det. Kemudian arus pasang ketiga (pukul 16.30-19.00 Wita), arus mengarah ke selatan, timur laut, dan barat laut dengan kecepatan ratarata $19,40 \mathrm{~cm} /$ det. Kecepatan rata-rata arus saat surut adalah $13,30 \mathrm{~cm} /$ det dan saat pasang adalah $11,90 \mathrm{~cm} /$ det (Gbr. 3).

Di stasiun 2, ketika arus pasang pertama (pukul 20.00-21.00 Wita), arus yang mengarah ke tenggara dan barat daya dengan kecepatan ratarata arus adalah $6,70 \mathrm{~cm} /$ det. Arus surut pertama (pukul 22.00-03.00 Wita) dominan mengarah ke selatan dengan kecepatan rata-rata $8,30 \mathrm{~cm} / \mathrm{det}$, 

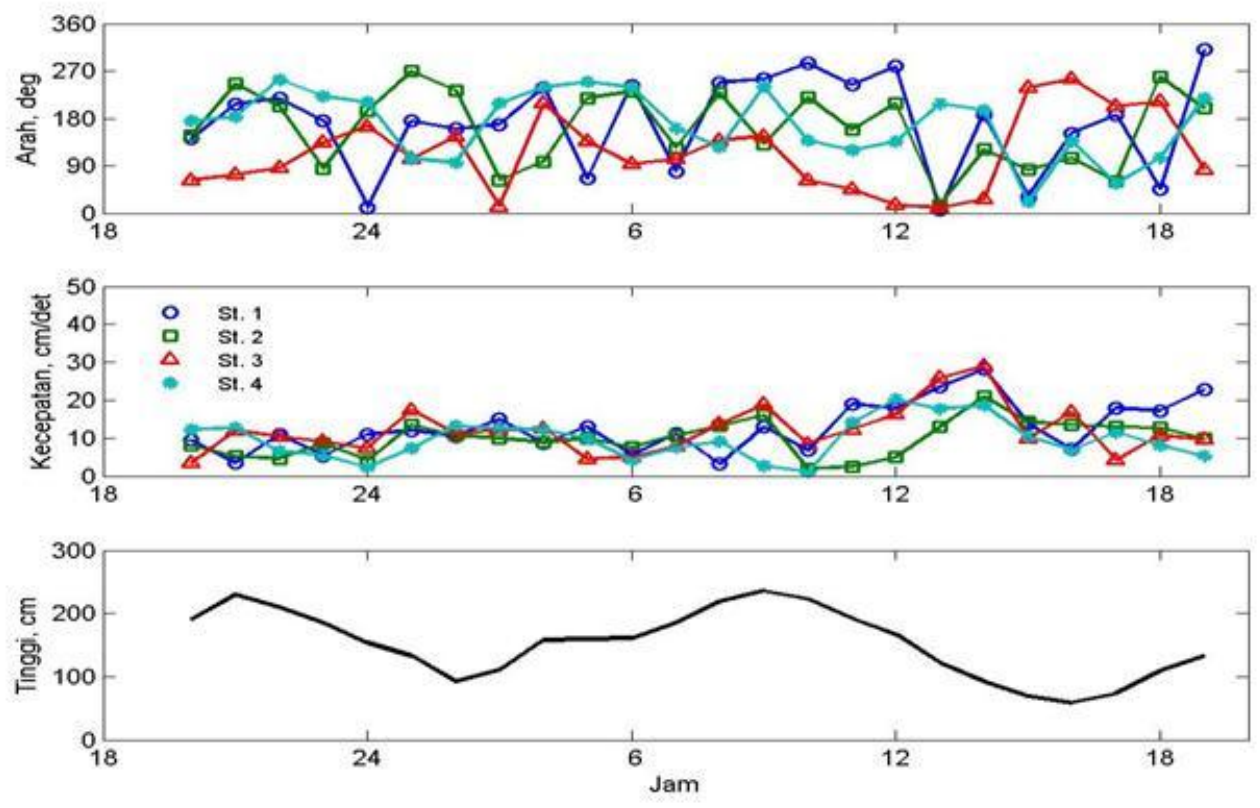

Gambar 3. Arah dan kecepatan arus menurut pergerakan pasang surut saat bulan bulan baru ke perbani awal

sedangkan arus relatif mengarah ke timur laur, barat daya dan tenggara saat pasang kedua (pukul 03.00-09.00 Wita) dengan kecepatan rata-rata 11 $\mathrm{cm} /$ det. Saat arus surut kedua (pukul 09.30-16.00 Wita), arus dominan mengarah ke timur dengan kecepatan rata-rata $10,20 \mathrm{~cm} /$ det. Kemudian arus pasang ketiga (pukul 16.30-19.00 Wita), arus mengarah ke timur laut, barat, dan selatan dengan kecepatan rata-rata $11,90 \mathrm{~cm} /$ det. Kecepatan ratarata arus saat surut adalah $9,30 \mathrm{~cm} /$ det dan saat pasang adalah $9,80 \mathrm{~cm} /$ det (Gbr. 3).

Pengamatan di stasiun 3 terlihat bahwa arah arus pasang pertama (pukul 20.00-21.00 Wita) ke timur laut dan timur dengan kecepatan rata-rata arus sebesar 7,70 $\mathrm{cm} /$ det. Sedangkan arus surut pertama (pukul 22.00-03.00 Wita) mengarah ke timur dan selatan dengan kecepatan rata-rata 11,10 $\mathrm{cm} /$ det. Arah arus ke timur dan tenggara saat arus pasang kedua (pukul 03.00-09.00 Wita), dengan kecepatan rata-rata $10,70 \mathrm{~cm} /$ det. Sedangkan arus surut kedua (pukul 09.30-16.00 Wita) dominan mengarah ke timur laut, dengan kecepatan ratarata sebesar $17,00 \mathrm{~cm} /$ det. Kemudian arus pasang ketiga (pukul 16.30-19.00 Wita) dominan mengarah ke barat daya dengan kecepatan ratarata $8,20 \mathrm{~cm} /$ det. Kecepatan rata-rata arus saat surut adalah $14,10 \mathrm{~cm} /$ det dan saat pasang adalah $8,90 \mathrm{~cm} / \operatorname{det}$ (Gbr. 3).

Pengamatan di stasiun 4 terlihat bahwa arah arus pasang pertama (pukul 20.00-21.00 Wita) mengarah ke selatan dengan kecepatan rata-rata arus sebesar $12,50 \mathrm{~cm} /$ det. Sedangkan arus surut pertama (pukul 21.00-03.00 Wita) mengarah ke barat daya dan timur dengan kecepatan rata-rata 7 $\mathrm{cm} /$ det. Arah arus dominan ke barat daya saat arus pasang kedua (pukul 03.00-09.00 Wita), dengan kecepatan rata-rata $8,30 \mathrm{~cm} /$ det. Sedangkan arus surut kedua (pukul 09.30-16.00 Wita) dominan mengarah ke tenggara dengan kecepatan rata-rata sebesar $12,80 \mathrm{~cm} /$ det. Kemudian arus pasang ketiga (pukul 16.30-19.00 Wita) mengarah ke timur laut, tenggara, dan barat daya dengan kecepatan rata-rata $8,30 \mathrm{~cm} /$ det. Kecepatan ratarata arus saat surut adalah $9,90 \mathrm{~cm} /$ det dan saat pasang adalah $9,70 \mathrm{~cm} / \operatorname{det}(\mathrm{Gbr} .3)$.

\section{KESIMPULAN}

Dari data kecepatan arus yang didapat selama 3 kali survei yang dilakukan, kecepatan arus bervariasi mulai dari $1,40 \mathrm{~cm} /$ det sampai dengan $42,50 \mathrm{~cm} /$ det. Kecepatan arus terendah sebesar 
$1,40 \mathrm{~cm} /$ det tercatat pada periode bulan purnama saat air surut pertama, sedangkan kecepatan arus tertinggi sebesar $42,50 \mathrm{~cm} / \mathrm{det}$ tercatat pada periode perbani akhir saat arus surut kedua.

Saat bulan purnama, arus dengan kecepatan rendah umumnya pada kawasan dekat garis pantai dan berada di tengah perairan. Sedangkan pada kawasan yang mendekati tanjung Mandolang kecepatan arus meningkat. Saat perbani akhir, kecepatan arus tertinggi diperoleh pada kawasan yang dekat dengan garis pantai dan berada di tengah perairan. Pada saat antara bulan baru dan perbani akhir, daerah yang berada di tengah perairan memiliki kecepatan arus yang tinggi. Daerah yang berada di ujung perairan memiliki kecepatan arus yang rendah.

Pergerakan arus pada bulan purnama saat surut lebih banyak bergerak ke barat daya dan saat pasang lebih banyak bergerak ke timur laut. Pergerakan arus pada perbani akhir saat surut lebih banyak bergerak ke timur laut dan saat pasang lebih banyak bergerak ke selatan dan barat daya. Di antara bulan baru ke perbani awal, pergerakan arus saat surut lebih banyak ke tenggara, selatan, barat daya dan saat pasang lebih banyak ke barat daya.

Stasiun 4 saat di antara bulan baru dan perbani awal merupakan fishing ground yang baik untuk melakukan operasi penangkapan bagan apung dikarenakan kecepatan arus dan perubahan kecepatan arus tiap jam yang relatif rendah. Waktu yang baik untuk pengoperasian bagan apung di stasiun 4 adalah pada pukul 22.00-24.00 dan pukul 03.00-06.00 disebabkan pada waktu tersebut arus tidak mengalami perubahan arah yang signifikan.

\section{DAFTAR PUSTAKA}

Anonimous. 2002. Atlas Sumberdaya Wilayah Pesisir dan Laut Manado-Bitung-Minahasa-Bolmong. Badan Perencanaan, Penelitian dan Pengembangan.

BAKOSURTANAL. 1995. Peta Lingkungan Pantai Indonesia. Lembar LPI 2417:01-07, Jakarta.

Baskoro, M.S., R.I.Wahyu, dan A. Effendy. 2004. Migrasi dan Distribusi Ikan. IPB, Bogor.

DISHIDROS. 2010. Daftar Pasang Surut (Tide Tables) Kepulauan Indonesia (Indonesian Archipelago) TNI-AL Dinas Hidro-Oseanografi, Jakarta. Hal. 543-544

Djaja, R. 1989. Pengamatan pasang surut laut untuk penentuan datum ketinggian. Dalam: O.R.R. Ongkosongo dan Suyarso (Penyunting). Pasut. P3O-LIPI, Jakarta. Hal 149-191.

Duxbury, A.B. dan A.C. Duxbury. 1993. Fundamentals of Oceanography. WM, C. Brown Publisher, United States of America.

Ingmanson, D.E. dan W.J. Wallace. 1989. Oceanography, An Introduction. Wadsworth Publishing Company Belmont, California.

Monintja D.R dan S. Martasuganda. 1991. Teknologi Pemanfaatan Sumberdaya Hayati Laut II. IPB Press, Bogor.

Nontji, A. 1987. Laut Nusantara. Penerbit Djambatan, Jakarta.

Pariwono, J.L. 1989. Kondisi pasang surut di Indonesia. Dalam: O.S.R. Ongkosongo dan Sunaryo (Penyunting). Pasut, P3O-LIPI, Jakarta. Hal 135-147.

Pickard, G.L. dan W.J. Emery. 1982. Descriptive physical oceanography: An introduction. Pergamon Press, Oxford.

Poerbandono, N. dan E. Djunasjah. 2005. Survey Hidrografi. Refika Aditama, Bandung.

Rampengan, R.M. 2009. Pengaruh pasang surut pada pergerakan arus permukaan di Teluk Manado. Jurnal Perikanan dan Kelautan V(3): 15-19.

Royce, W.F. 1983. Introduction of Fishery Science. Academic Press, New York.

Subani, W. dan H.R. Barus. 1989. Alat penangkapan ikan dan udang di Indonesia. Jurnal Penelitian Perikanan Laut Nomor 50 (Edisi Khusus).

Wibisono, M.S. 2005. Pengantar Ilmu Kelautan. Grasindo, Jakarta. 